\title{
A linguagem poética em Anne With An E
}

\author{
Luise Mariano Bertolino1 \\ Míriam Cristina Carlos Silva²
}

\begin{abstract}
Resumo
O presente artigo tem como tema a linguagem poética na série de televisão Anne With An E (2017) adaptada por Moira Walley-Becket, a partir do livro Anne de Green Gables (1908), de Lucy Maud Montgomery. Para refletirmos sobre o poético, delimitamos como corpus o primeiro episódio da série, "Sua determinação dita seu destino", dirigido por Niki Caro. Pretendemos identificar a linguagem poética construída a partir do olhar e da recriação de mundo da personagem Anne, e de que forma isso se apresenta na construção da narrativa por meio da fotografia e dos cenários.
\end{abstract}

Palavras-chave: Comunicação poética. Audiovisual. Fotografia.

\begin{abstract}
This present article has as theme the poetic language on the television series Anne With An E (2017) adapted by Moira Walley-Becket, from Lucy Maud Montgomery's book "Anne of Green Gables" (1908). To reflect on the poetic, we delimited the first episode of the series as a corpus, "Your Will Shall Decide Your Destiny", directed by Niki Caro. We intend to identify the poetic language constructed from Anne's viewpoint, her world recreation and how this is presented on the narrative's construction through photography and scenery.
\end{abstract}

Keywords: Poetic communication. Audio-visual. Photography.

\section{Introdução}

Este artigo integra a pesquisa de mestrado em andamento sobre a linguagem poética e a transformação do feminino na série Anne With An E. Para desenvolvê-lo nos limitaremos ao aspecto analítico da linguagem poética apresentada nas cenas do primeiro episódio da série, intitulado "Sua determinação dita seu destino". A fim de identificar

\footnotetext{
${ }^{1}$ Mestranda em Comunicação e Cultura pela Universidade de Sorocaba. E-mail: luise.bertolino@gmail.com

${ }^{2}$ Doutora em Comunicação e Semiótica (PUC-RS) e professora do PPGCOM em Comunicação e Cultura da Universidade de Sorocaba. E-mail: miriam.silva@prof.uniso.br
} 


\section{VOZES $_{\text {\&IÁLORO }}^{\mid}$}

Itajaí, V. 20, n.01, jan-jun 2021

aspectos poéticos na obra audiovisual, escolhemos como recorte a construção da poeticidade por meio da fotografia que, associada como estratégia narrativa, promove a composição do espaço na relação com os personagens, situa o contexto histórico e cria elementos simbólicos que evidenciam a dramaticidade apresentada no enredo.

Para o embasamento teórico do artigo, escolhemos como os principais autores, Iuri Lotman e Miriam Cristina Carlos Silva. Com Lotman, desenvolveremos as noções advindas da semiótica da cultura sobre os processos tradutórios entre diferentes linguagens na composição do texto artístico. Com Silva, abordaremos as estratégias narrativas na construção da poeticidade, teceremos suas relações com os processos comunicacionais e de que forma se consolidam no produto midiático a ser analisado.

O objetivo geral do artigo é identificar os elementos poéticos da série Anne With An $E$ a partir do entrelaçamento da fotografia com a narrativa, para enfatizar que a poética se sustenta na imagem, em interação com outras referências, tais como as descrições e ações da protagonista, por exemplo, na recriação do mundo através do olhar da personagem Anne. Os objetivos específicos tratam de identificar quais são os elementos narrativos que possuem força poética notável e que merecem ser descritos, analisados e avaliados, como imagens, textos, trilhas sonoras, enquadramentos, passagens de plano, sequência de cenas na composição da montagem; e compreender de que forma esses elementos se entrelaçam com as imagens na construção da linguagem poética.

Para identificar os elementos poéticos da série Anne With An E, apresentaremos os conceitos de texto artístico, segundo Lotman, e de que forma esses elementos apresentam-se nos produtos midiáticos a partir de Silva. Em seguida, estabelecendo relações com os autores, levantaremos os elementos que constroem a linguagem poética no episódio "Sua determinação dita seu destino", e quais as estratégias narrativas que, entrelaçadas à fotografia, apresentam as características da personagem Anne, sua interação com o espaço e como revelam suas percepções de mundo. Assim, na primeira sessão deste trabalho, abordaremos a fundamentação teórica que nos guiará na compreensão dos aspectos poéticos na narrativa audiovisual.

\section{A comunicação poética}

De acordo com Iuri Lotman (1978), a arte é um dos meios de comunicação, por realizar a ligação entre um emissor e um receptor, com a finalidade de passar uma mensagem. E todo sistema que serve para os fins de comunicação entre dois ou vários indivíduos pode ser definido como linguagem. Silva (2010) acrescenta que a arte é uma das formas mais plenas de comunicação, por necessitar de um emissor e de um receptor atento, com todos os seus sentidos em alerta, o que dá abertura à possibilidade de uma experiência. Segundo Lotman (1978), qualquer linguagem representa uma determinada estrutura na combinação de signos; e o texto artístico, enquanto linguagem, é construído com uma 


\section{VOZES $_{\text {\&IÁLORO }}^{\mid}$}

Itajaí, V. 20, n.01, jan-jun 2021

estrutura complexa, na qual todos seus elementos são elementos de sentido. Silva (2010) propõe atualizar o conceito lotmaniano de "texto artístico", tomando-o como sinônimo de signo poético, e que tal complexidade, em sua estrutura, justifica-se quando, em contato com o fruidor da obra, ampliam-se as possibilidades de experiência e atribuição de sentidos.

Silva (2010) ressalta que a noção de texto, para Lotman, é um conjunto estruturado de códigos verbais ou não-verbais, cuja finalidade é passar uma mensagem. Também afirma que os produtos dos media estão permeados de poeticidade com mensagens estruturadas de forma complexa, e destaca a pertinência de abordar as "especificidades do signo poético, das marcas que permitem identificá-lo e do modo como opera, fazendo dele uma linguagem singular, já que este poético pode caracterizar parte significativa dessa produção mediática” (SILVA, 2010, p. 280).

Para Lotman (1978), a comunicação artística cria o modelo artístico de um fenômeno concreto, porque ela reconstitui uma imagem da realidade. Por outro lado, ao reconstituir uma dada realidade, há a proposição de um novo modelo de mundo. Assim, a linguagem da arte modeliza os aspectos mais gerais da imagem do mundo, sendo que sua estrutura pode ser o conteúdo fundamental da obra, que poderá tornar-se, ela mesma, como estrutura, a própria informação, ou seja, a arte comunica a sua estrutura, a sua forma. De acordo com Lotman (1978), se uma estrutura artística complexa transmite uma certa informação impossível por meio de outra estrutura de linguagem, essa informação resulta em um conteúdo que não pode ser transmitido fora desta estrutura específica. Portanto, um conteúdo transmitido por uma linguagem complexa não pode ser reduzido a uma estrutura simplificada. Caso haja sua tradução, esta somente poderá ser realizada por meio de outra estrutura complexa.

Lotman (1978) afirma que a língua é uma estrutura modelizante primária, que serve como modelo para todas as outras estruturas de linguagem, que poderão ser comentadas, estudadas, analisadas e descritas por meio da língua. A arte, segundo o autor, constitui uma estrutura modelizante secundária, composta pelo conjunto das linguagens do teatro, do cinema, da pintura, da música, entre outras, que envolvem a arte no seu conjunto, como linguagens organizadas, individualmente, de modos particulares. Ou seja, embora o grande conjunto da linguagem da arte guarde características em comum, tais como a ideia de complexidade, na qual conteúdo é forma e forma é conteúdo, cada linguagem da arte possui suas especificidades.

Neste artigo relacionaremos a linguagem do cinema à linguagem audiovisual, que utiliza signos ordenados de modo particular, o que a diferencia de outras linguagens. $\mathrm{O}$ audiovisual, como todas as linguagens, possui regras definidas na combinação de signos, e os signos em arte não têm um caráter convencional, como na linguagem informativa, "mas um caráter icônico, figurativo” (LOTMAN, 1978, p. 55). Segundo o autor, o discurso poético é mais complexo que a língua natural, e a "complexificação do caráter da 


\section{VOZES $_{\text {\&IÁLORO }}^{\mid}$}

Itajaí, V. 20, n.01, jan-jun 2021

informação arrasta inevitavelmente a complexificação do sistema semiótico bem construído, ou seja, num sistema bem elaborado, não pode haver complexidade supérflua, não justificada” (LOTMAN, 1978, p. 38).

"O mundo visto poeticamente é um mundo novo" (SILVA; GABRIEL, 2017, p. 96), e as narrativas possuem capacidade de criar e recriar o mundo que nos cerca (SILVA, 2015). Para Silva (2007), o poético não está restrito apenas ao campo artístico, mas se trata de uma qualidade da linguagem, que envolve a abertura e a participação do receptor, e, também pode ser apreendido no cotidiano, com objetos, cenas, paisagens, cores, que se iluminam sob uma perspectiva sensível e polissêmica. Desta forma, podemos identificar a presença do poético nas mídias, seja na publicidade, nas novelas, no jornalismo ou nos seriados de TV.

Assim, as narrativas audiovisuais contemporâneas, quando elaboradas com uma estrutura complexa e, ao oferecerem outros modelos possíveis de experimentar o mundo, podem transformar nosso olhar para o cotidiano. O poético, por sua polissemia, ambivalência, economia, densidade e sinestesia pode conduzir a uma experiência sensível, capaz de renovar a compreensão dos fenômenos que nos cercam (SILVA; GABRIEL, 2017).

\section{A linguagem poética em Anne With An E}

Considerando os conceitos apresentados pelos autores, percebemos a série Anne With An Ecomo um produto midiático que, a partir da linguagem audiovisual, explorou diversos recursos artísticos, com elementos visuais carregados de poeticidade, que entrelaçados à narrativa, compõem uma estrutura complexa para conduzir o espectador à experiência, que pode possibilitá-lo sentir a história junto à personagem.

O primeiro episódio da série Anne With An E, "Sua determinação dita seu destino", compõe o eixo central da construção da personagem e do próprio enredo, apresentando-se como um prólogo da obra audiovisual composta de três temporadas, pois muitos dos elementos que serão desenvolvidos nos episódios seguintes, revelam-se pela primeira vez nesse episódio. Trata-se de componentes fundamentais para $o$ desenvolvimento da narrativa, que nos auxiliam a compreender quem é a personagem Anne e como lida com suas experiências a partir de suas visões de mundo.

A narrativa se inicia em ponto de clímax, com as expectativas da órfã Anne ser adotada pelos irmãos Cuthbert. Na viagem de trem a caminho de uma nova vida, o passado de Anne é revelado a partir de suas lembranças na casa de uma família que a adotou anteriormente, onde era explorada, agredida, e são cenas com a paleta de cores frias, com tons azulados, que pode ser um recurso visual para indicar a tristeza, e contrastar com as expectativas de mudança para uma nova família, que é retomada no corte seguinte. Retornando ao presente, Anne diz que prefere imaginar a lembrar; ela questiona por que 


\section{VOZES $_{\text {\&IÁLORO }}^{\mid}$}

Itajaí, V. 20, n.01, jan-jun 2021

as piores lembranças permanecem, e cita um trecho do livro Jane Eyre, de Charlotte Brönte, aplicando a referência literária em sua própria história de vida. Assim, é apresentada uma das principais características da personagem, que é a importância da imaginação e da poeticidade em suas visões de mundo. O livro Jane Eyre é um dos elementos que retornam em outros episódios, em cenas de lembranças tristes do orfanato onde também viveu. Anne lia o livro escondida, e revela, posteriormente, que a leitura salvou sua vida, pois era seu refúgio mental em meio a tanto sofrimento. Vale acrescentar que os títulos dos episódios da primeira temporada são frases do livro Jane Eyre.

Outra estratégia poética na composição da narrativa, trata-se da forma como a interação de Anne com o cenário auxilia na construção da personagem, onde identificamos a cerejeira branca como um signo poético não-verbal, que compõe um elemento de sentido, icônico e figurativo, como vimos nos conceitos de texto artístico proposto por Iuri Lotman. Ao desembarcar na estação de trem, ainda envolvida em grandes expectativas em relação à adoção, Anne se depara com uma cerejeira branca, que é um elemento presente do início ao fim do episódio. A cerejeira branca é a primeira relação de afeto que a personagem desenvolve com o espaço e simboliza um momento epifânico em que Anne percebe que está mudando sua história de vida.

Matthew Cuthbert chega à estação para buscar a criança que seria adotada e pergunta para um funcionário sobre um menino que chegaria de um orfanato, mas o funcionário informa que só há uma menina "tagarela”, que preferiu ficar do lado de fora da estação porque teria mais alcance à imaginação. No primeiro diálogo de Anne com Matthew ela relata que estava preocupada se ele realmente apareceria para buscá-la, e caso não aparecesse, ela caminharia pelo trilho até a cerejeira, subiria nela e passaria a noite lá. Diz que "seria maravilhoso dormir numa árvore em flor sob o luar" que remete a uma das frases utilizadas na abertura do seriado. Num plano em close com um aperto de mãos entre eles, Anne não solta as mãos de Matthew durante todo o longo diálogo, e ele a solta delicadamente. Nessa imagem percebemos a tristeza dele em relação ao equívoco de trazerem uma menina e não um menino. Ao saírem da estação de trem, Anne se despede da cerejeira branca, e diz que foi sua primeira amiga na ilha.

Em todos os momentos em que a cerejeira retorna, ela se desdobra em novas epifanias, na percepção de mundo no qual ela está se inserindo, levando o fruidor da narrativa ao mundo poético que a personagem constrói. Chegando à fazenda de Green Gables, Anne se encanta com a beleza do novo lar, e num plano aberto da casa, vemos uma cerejeira branca ao fundo. No entanto, Anne é informada por Marilla Cuthbert que eles não esperavam por uma menina, mas sim um menino para auxiliar nos trabalhos da fazenda. A senhora diz que Anne será devolvida para o orfanato no dia seguinte, e a menina sofre com a rejeição. Ao amanhecer, Anne abre a janela e encontra a cerejeira branca: na fotografia, a luz do sol ilumina apenas o seu rosto; ela colhe um galho da árvore e diz "aceito sua oferenda. Tivesse eu um livro, colocaria estas flores sagradas entre as páginas para me 


\section{VOZES $_{\text {\&IÁLORO }}^{\mid}$}

Itajaí, V. 20, n.01, jan-jun 2021

lembrar para sempre deste momento tão precioso. No entanto, eu, Princesa Cordélia, estimarei este presente para sempre. Que meu beijo prove minha devoção". Ao ser interrompida por Marilla, Anne diz que estava imaginando aquela manhã diferente do que realmente era, que ela seria uma princesa num quarto sagrado no alto de uma torre de pedra, e que a cerejeira deu a ela alcance à imaginação. Antes de partir, Anne guarda um galho da cerejeira na mala. Essas cenas são fundamentais na construção da personagem ao revelar seu olhar poético em relação ao ambiente, e na reconstrução de uma nova realidade a partir da imaginação.

Anne se prepara para retornar ao orfanato, e se despede da casa observando cada objeto, cada detalhe para levar em suas memórias. Nesse momento, ela passa por um quadro de uma foto com três crianças, e esse quadro é um elemento que se apresenta neste episódio, e se desdobra posteriormente em significados. Na foto estão Marilla, Matthew e um irmão que faleceu, e nos episódios seguintes, é revelado como a morte do irmão mudou o destino dos Cuthbert, o motivo de dois irmãos idosos e solteiros cuidarem sozinhos da fazenda, e como isso influenciou em suas personalidades. Ao ver Anne tocando nos objetos, Marilla se irrita e questiona se ela estava roubando a casa antes de partir; ela abre a mala de Anne para conferir e encontra o galho da cerejeira. Marilla joga o galho no fogo a lenha do fogão, queimando qualquer esperança da menina em ter um lar, uma família e viver em Green Gables. Ao partir da fazenda, Anne diz "Minha vida é um cemitério de esperanças enterradas”, frase componente da abertura, que indica que ela já sofrera com a rejeição diversas vezes.

Outros objetos presentes no primeiro episódio são elementos de sentido que se desdobram ao longo do seriado, revelando camadas de significados. Como um laço de fita azul que Marilla coloca no cabelo de Anne, que posteriormente, é revelado como um objeto de valor sentimental, o qual Marilla ganhou de um antigo pretendente com quem viveu um romance interrompido na juventude, em consequência de ter que assumir as responsabilidades da fazenda após a morte do irmão.

Seguidas algumas reviravoltas no enredo, Marilla decide testar a possibilidade de Anne permanecer na fazenda. A menina está em êxtase, colhe algumas flores da cerejeira e pergunta se pode levá-las para o quarto; Marilla nega. Os galhos floridos são colocados em um vaso na mesa da sala. Quando ocorre um mal-entendido, Marilla acusa Anne de roubar um broche, e a leva embora pela segunda vez; a senhora vê uma flor caindo desse galho de cerejeira no vaso. Na fotografia, a flor cai em slow motion, de um plano médio dos galhos floridos, para um close-up da flor caindo na mesa, ao que Marilla reage como um alerta. Chegando ao seu quarto, Marilla encontra o broche perdido em uma cadeira, e percebe que cometeu um grande equívoco, e manda Matthew buscar Anne de volta. Mas quando ele chega à estação, o trem já partiu. Matthew, desolado, olha para a cerejeira branca da estação, como um elemento de gatilho para uma distante lembrança da presença de Anne, que partira. 


\section{VOZES $_{\text {\&IÁLORO }}^{\mid}$}

Itajaí, V. 20, n.01, jan-jun 2021

Assim, percebemos como a cerejeira branca auxiliou na construção da personagem e da poética na narrativa. A percepção de Anne para a árvore ultrapassa o enredo na elaboração de uma estrutura complexa em torno de um signo poético que acaba contaminando tudo: o cenário, os diálogos, criando um vínculo com os outros personagens, logo, a árvore se torna uma metonímia ao remeter à presença de Anne e suas visões poéticas de mundo reveladas ao longo do episódio.

A linguagem poética também é mencionada diretamente em alguns diálogos de Anne, quando ela diz que a oração parece uma poesia. A religiosidade não integrava os costumes da personagem, no entanto, percebemos como ela experimenta o sagrado com todos os seus sentidos ao aprender a proferir as orações. De acordo com Pichiguelli e Silva (2017), a religiosidade parte do cotidiano e o reinventa, dando a ele novos significados; explode como poesia a partir da reconexão do corpo, supostamente profano, com a celebração do sagrado, em uma experiencia transcendente, conduzida para além do cotidiano por uma linguagem que aciona hiperbolicamente todos os sentidos; é "uma forma de transcendência, que, por meio das metáforas, propicia conexões criativas entre os seres e as coisas do mundo" (PICHIGUELLI; SILVA, 2017, p. 14).

Percebemos essas conexões sagradas conectadas aos sentidos quando Anne recita o Pai-Nosso em voz alta, com alegria e sincera gratidão, movimentando o corpo em giros, e na fotografia, a câmera em contra-plongée mostra Anne em sua celebração com o céu ao fundo. Ela também recita a oração com melodia e diz que parece música. Em outra cena, Anne diz sobre as orações: "Há algo de esplêndido em algumas das palavras. Infinito e imutável. Não é exatamente poesia, mas soa parecido, não?”. Atribuindo novos significados e reinventando a conexão sagrada, Anne propõe uma nova forma de acionar os sentidos do corpo na experiência transcendente quando ela questiona "Por que preciso me ajoelhar? Se quisesse mesmo rezar, vou dizer o que eu faria. Eu iria a um campo aberto enorme, completamente sozinha, ou a uma floresta bem fechada, e olharia para o céu, bem para cima, para aquele adorável céu azul infinito e simplesmente sentiria a prece”.

Se as narrativas poéticas possuem capacidade de criar e recriar o mundo que nos cerca (SILVA, 2015), percebemos essa característica personificada em Anne. Na cena em que Matthew a leva pela primeira vez para a fazenda Green Gables, durante a viagem de carroça na estrada, Anne diz que adora usar palavras difíceis para expressar grandes ideias, frase que também compõe a abertura, pois existem palavras estimulantes e descritivas. Ela se encanta com a bela paisagem que encontra, representada na fotografia em planos abertos dos cenários naturais da Ilha do Príncipe Eduardo, com uma trilha sonora alegre, que nos transmite as sensações de Anne, a qual se diz extasiada por aquela paisagem gloriosa ser seu novo lar.

Posteriormente, com imagens da carroça passando por um exuberante trecho florido, na fotografia ressaltado com as luzes do sol oscilando com o movimento do veículo, em composição com uma trilha sonora emotiva, Anne diz que é a primeira coisa que ela 


\section{VOZES $_{\text {\&IÁLORO }}^{\mid}$}

Itajaí, V. 20, n.01, jan-jun 2021

vê que não pode ser melhorada com a imaginação. Ela pergunta qual o nome daquele lugar, e Matthew responde "Avenida. Acho que é bem bonita", e Anne diz "Bonita não é a palavra adequada, nem bela. Elas não vão tão longe. Ela é maravilhosa! (...) Podem chamar de Avenida, mas eu sempre chamarei de Estrada Branca do Deleite”. Matthew segue dizendo o nome dos lugares, e Anne os renomeia, como a Lagoa do Barry, da qual a fotografia em plano aberto mostra o lago refletindo a imagem das árvores. Anne o chama de Lago das Águas Brilhantes. Assim, o olhar da personagem nos oferece outros modelos possíveis de experimentar o mundo, e modifica o nosso próprio olhar sobre os fenômenos que nos cercam. Segundo Silva e Gabriel (2018), a arte transforma o nosso olhar para o cotidiano, que se torna poético. "O poético é, portanto, linguagem, pensamento e modo de olhar para o mundo que nos afeta” (SILVA; GABRIEL, 2018, p. 96).

A linguagem poética também se apresenta em Anne With An Equando relacionamos aspectos trágicos e heroicos citados diretamente em seus diálogos e presentes na composição de sua própria narrativa. Lembramos a Poética de Aristóteles (2003), autor clássico que teorizou as primeiras noções de poesia, remodeladas ao longo dos tempos por autores diversos, até os contemporâneos. Aristóteles (2003) conceituou os elementos componentes da tragédia e a reconhece como a mais nobre representação artística e poética, pois imita homens superiores, contém ações de caráter elevado, com linguagem ornamentada, abarca elementos do drama e da poesia épica, "e que, suscitando o terror e a piedade, tem por efeito a purificação dessas emoções" (p. 110). No episódio "Sua determinação dita seu destino”, Anne cita a tragédia diversas vezes em seus diálogos. Na viagem de trem, antes de conhecer os irmãos Cuthbert, ela se diz curiosa do porquê deles nunca se casarem: "Será que um deles teve um romance trágico?". Quando sofre a primeira rejeição de Marilla por ser uma menina, e a senhora pergunta seu nome, Anne responde "Por favor, me chame de Cordélia. Ou Penélope. Penélope tem um quê de trágico”. Na cena do dia seguinte, no café da manhã, Anne conformada com a sua devolução ao orfanato diz: "É muito bom ler histórias tristes e se imaginar passando heroicamente por elas, mas não é fácil se está triste, não?”. Em seguida, na carroça partindo de Green Gables, Anne conta para Marilla como ficou órfã. Ela começa a narrativa nos moldes de um conto de fadas, mas Marilla se irrita e pede que conte sua história verdadeira, então, Anne conta sua história trágica que iniciou quando ainda era um bebê. O diálogo é interrompido por um cachorro que aparece latindo na estrada e assusta a égua que conduzia a carroça. A montagem da cena é uma sequência de imagens rápidas, entre planos detalhes e médios dos animais, como num susto que acontece numa fração de segundos. Anne cai da carroça, mas levanta e heroicamente espanta o cachorro da estrada, acalma a égua e sorrindo diz a Marilla "Não foi uma aventura?". São cenas que acrescentam elementos à composição da personagem, apresentam as características trágicas inerentes a sua história, mas também a bravura heroica de uma criança destemida ao enfrentar os seus 


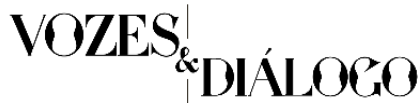

Itajaí, V. 20, n.01, jan-jun 2021

problemas. Podemos relacionar como elementos de metalinguagem quando percebemos essas referências diante da composição narrativa como um todo.

Retomando os conceitos da Poética de Aristóteles (2003), observamos a narrativa de Anne como a mais nobre representação artística com aspectos da tragédia ressaltados pela rejeição e o abandono. A tragédia de Anne pertence ao período histórico da modernidade, que obteve sua máxima ascensão no século XIX, quando houve o maior movimento de massas migratórias para as américas, que favorece o deslocamento cultural de uma menina cujas características étnicas destoam do local no qual foi inserida. Isso resulta na rejeição dos outros e de si mesma, quando revela que sua maior tristeza é ser ruiva. Dissociada da família, Anne é uma órfã que passa por grandes dificuldades de aceitação, representadas em cenas que suscitam terror e piedade, e se opõem às expectativas do fruidor que se apieda diante de tais acontecimentos, por reconhecer os valores nobres da personagem. Ultrapassando a observação para a série como um todo, a partir dos fundamentos da tragédia pela nobreza que Anne ressalta, a personagem eleva seu exponencial quando traz a defesa das mulheres, da questão indígena, do negro, e da divisão social, temas abordados ao longo das três temporadas.

A fotografia mostra-se um elemento fundamental na composição da narrativa, pois torna nobres os valores subalternos, ou, sofisticado ao que era rejeitado. $\mathrm{E}$ no jogo de tensão conduzido pelo enredo, identificamos a presença dos principais aspectos da tragédia segundo a teoria aristotélica: a imitação de uma pessoa com valores nobres, a recriação do mundo através da poesia, o relaxamento diante de pequenos trechos de comédia, e a erudição pelo uso da linguagem ornamentada em diálogos da personagem. Esses elementos são ressaltados pela fotografia para o deleite das imagens, o que permite que a série Anne With An $E$ proporcione uma experiência sensível.

\section{Considerações finais}

O audiovisual, enquanto linguagem, é capaz de abarcar diversos elementos de sentido, tanto os verbais, a partir dos textos nos diálogos, como os não-verbais presentes nos sons e nas imagens. Após o levantamento de tais elementos carregados de poeticidade na série Anne With An $E$, percebemos como todos se entrelaçam em uma composição complexa na construção da narrativa, dos personagens, do cenário e do espaço. Trata-se de um produto cultural e midiático produzido com recursos artificiais do audiovisual que, em contato com o fruidor, são "responsáveis por produzir comunicabilidade, criando vínculos, identidade, memória, interpretações, reflexões e até mesmo transformando os fenômenos concretos” (SILVA; CAMARGO, 2018, p. 136).

Podemos afirmar que a série Anne With $A n E$ é um texto artístico, amparadas em Lotman (1978), pois consiste em uma forma de comunicação econômica que abriga um enorme potencial comunicacional, por seu caráter denso e polissêmico; e, também, em 


\section{VOZES $_{\text {\&IÁLORO }}^{\mid}$}

Itajaí, V. 20, n.01, jan-jun 2021

Pichiguelli e Silva (2017), por cumprir o papel de representar o mundo dos fenômenos concretos, ao mesmo tempo em que cria um outro modelo de mundo e outras possibilidades poéticas.

Anne é uma personagem essencialmente poética, o que é ressaltado em sua trágica história de vida e na forma como supera os problemas que enfrenta. A imaginação é sua característica fundamental para ver o mundo com outros olhos, para reinventá-lo, para transformar o que é trágico em belo e, o banal em poético. Envolve as referências literárias nesse processo de reinvenção, atribuindo elementos de outras narrativas contextualizados à sua própria história. A personagem modifica o ambiente ao seu redor, atribuindo novos significados a elementos banalizados pelo cotidiano, e os eleva poeticamente quando os descreve vinculados a suas emoções, sentidos e imaginação. São olhares que auxiliam Anne a viver sua realidade com leveza, e são transformadores para os outros personagens que também modificaram seus olhares para o mundo em que vivem.

A distância de mais de um século entre o livro Anne de Green Gables e a série Anne With An E possibilitou à narrativa audiovisual a abordagem de temas relevantes para a sociedade contemporânea, tais como os direitos das mulheres, o racismo e a xenofobia. São temas que inserem uma narrativa situada no passado em um contexto relacionado com o presente, aproximando o público à narrativa por identificação, que pode ampliar as percepções de mundo e conduzir a reflexão dos fruidores para as situações que nos afetam na atualidade, além de possibilitar que Anne enfrente e protagonize tais situações expondo seu caráter elevado já evidente na obra literária.

O avanço tecnológico na captura de imagens em alta definição também auxilia a série na construção da poeticidade na linguagem audiovisual. Considerando a poesia como uma qualidade que transpõe a linguagem verbal, verificamos que está presente nas imagens da série de forma estratégica. Os produtores conseguiram traduzir com maestria o texto literário em fotografias, sons e recursos de edição e transição, oferecendo a possibilidade de enxergarmos o mundo como Anne o vê.

\section{Referências}

ARISTÓTELES. Poética. Lisboa: Imprensa Nacional Casa da Moeda, 2003.

LOTMAN, Iuri. A estrutura do texto artístico. Lisboa: Editorial Estampa, 1978.

PICHIGUELLI, Isabella; SILVA, Miriam Cristina Carlos. Comunicação, Poesia e o religare. Comunicologia: Revista de Comunicação da Universidade Católica de Brasília, v. 10, n.2, p. 3-18, dez. 2017. 


\section{VOZES $_{\text {\&DÁLOGO }}^{\mid}$}

Itajaí, V. 20, n.01, jan-jun 2027

SILVA, Miriam Cristina Carlos. Comunicação e Cultura Antropofágicas: mídia, corpo e paisagem na erótico-poética oswaldiana. Porto Alegre: Sulina, 2007.

SILVA, Miriam Cristina Carlos. Contribuições de Iuri Lotman para a Comunicação: Sobre a complexidade do signo poético. In: FERREIRA, G. M. Teorias da Comunicação: Trajetórias Investigativas. Porto Alegre: EdiPUCRS, 2010.

SILVA, Miriam Cristina Carlos. O infiltrado: narrativas midiáticas e uma poética antropofágica. Galáxia: São Paulo, n. 30, p. 125-137, 2015.

SILVA, Miriam Cristina Carlos; CAMARGO, Bruna Emy. Representações da morte nas narrativas midiáticas: a poética na novela Velho Chico. Verso e Reverso, v. 32, n. 80, p. 133-141, maio-ago. 2018.

SILVA, Miriam Cristina Carlos; GABRIEL, Gisele. O poético na comunicação ambiental: reflexões a partir da campanha A Natureza está falando. Tríade: Revista de Comunicação, Cultura e Mídia, Sorocaba, SP, v. 7, n. 15, p.93-112, ago. 2019.

SUA determinação dita seu destino (Temporada 1, ep. 1). Anne With $\boldsymbol{A n}$ $\boldsymbol{E}$ (Seriado). Direção: Niki Caro. Produção: Moira Walley-Beckett. Canadá: CBC, 2017. Netflix (89 min.), son., color. 